\title{
The transcription programme of the protein-primed halovirus $\mathrm{SH} 1$
}

Correspondence

Kate Porter

K.Porter@biota.com.au

Received 15 April 2008

Revised 29 June 2008

Accepted 15 August 2008

\author{
Kate Porter, ${ }^{1}$ Brendan E. Russ, ${ }^{2}{ }^{2}$ Yang $^{2}$ and Michael L. Dyall-Smith ${ }^{3}$ \\ ${ }^{1}$ Biota Holdings Ltd, 10/585 Blackburn Road, Notting Hill, Victoria 3168, Australia \\ ${ }^{2}$ Department of Microbiology and Immunology, University of Melbourne, 3052, Australia \\ ${ }^{3}$ Max-Planck Institute for Biochemistry, Department of Membrane Biochemistry, Martinsried 82152, \\ Germany
}

$\mathrm{SH} 1$ is the only reported isolate of a spherical halovirus, a dominant morphotype in hypersaline lakes. The virus lytically infects the haloarchaeon Haloarcula hispanica, and carries a $30.9 \mathrm{~kb}$ linear dsDNA genome that, in a previous study, was proposed to contain 56 protein-coding genes, probably organized into between four and eight operons. In the present study, these predictions were directly tested by determining the orientations and lengths of virus transcripts using systematic RT-PCR and primer extension. Seven major transcripts were observed that together covered most of the genome. Six transcripts were synthesized from early in infection $(1 \mathrm{~h}$ post-infection; p.i.) onwards, while transcript T6 was only detected late in infection (5-6 h p.i.). No transcripts were detected in the inverted terminal repeat sequences or at the extreme right end of the genome (ORFs 55-56). Start points for the major transcripts were mapped by primer extension and corresponded closely to the $5^{\prime}$ termini determined by RT-PCR. Between 1 and $4 \mathrm{~h}$ p.i., transcripts usually terminated not far beyond the end of their last coding ORF, but late in infection, transcripts from the same promoters often terminated at more distal points, resulting in much of the genome being transcribed from both strands. Since many of these transcripts are complementary, RNA-RNA interactions are likely, and may play a role in regulating viral gene expression. Puromycin blockage of post-infection protein synthesis significantly altered the levels of certain virus transcripts, indicating that de novo protein synthesis is essential for the correct regulation of $\mathrm{SH} 1$ gene expression.

\section{INTRODUCTION}

Viruses are ubiquitous, extremely diverse and occur in large numbers throughout the biosphere (Hendrix, 2002; Hendrix et al., 1999). In aqueous environments, virus concentrations are typically 10 -fold or higher than that of the microbial cells, upon which they effect a range of selective pressures (Bouvier \& del Giorgio, 2007; Weinbauer, 2004). While marine and fresh waters have been relatively well studied, far less is known about hypersaline waters, such as salt lakes, where salt concentrations hover around saturation. Under such harsh conditions the microbial diversity is severely restricted, mainly to extremely halophilic Archaea (Family Halobacteriaceae).

Abbreviations: IEP, isoelectric point; ITR, inverted terminal repeat; p.i., post-infection; VP, viral protein.

Two supplementary tables listing the oligonucleotide primers used in this study and the positions of the first and last ORFs relative to the inverted terminal repeats in protein-primed replication systems, and a supplementary figure showing the nucleotide sequence of the reference ladder used in the primer extension assays, are available with the online version of this paper.
Nevertheless, the cell densities are often very high and the virus concentrations even higher (Benlloch et al., 2002; Burns et al., 2004; Guixa-Boixareu et al., 1996; Oren et al., 1997). The majority of known archaeal viruses are not head-tail particles; instead, they encompass a range of novel groups and include many with unique morphologies (Prangishvili et al., 2006). The predominant virus-like particles in salt lakes are spindle-shaped and spherical (Guixa-Boixareu et al., 1996; Oren et al., 1997), but very few of these have been isolated and described (Dyall-Smith et al., 2003). On the other hand, head-tail particles appear to represent a minor proportion, yet have been the most commonly isolated. In non-extreme environments, such as marine and fresh waters, the great majority of bacteriophages are those with head-tail morphologies (Caudovirales) (Ackermann, 2007; Hendrix et al., 1999).

Halovirus $\mathrm{SH} 1$ is, to our knowledge, the only published isolate of a spherical halovirus, and was isolated in this laboratory from a salt lake sample taken in Western Australia (Porter et al., 2005). It is lytic, and infects Haloarcula hispanica, an experimentally convenient and genetically tractable haloarchaeon (Cline \& Doolittle, 1992; 
Woods et al., 1999). The virus replication cycle takes 5-6 h, and although cell lysis may occur at this time, delayed lysis is common, with cells continually shedding virus for several hours before eventually lysing (Porter et al., 2005). SH1 particles are $\sim 70 \mathrm{~nm}$ in diameter, with a fragile outer protein layer and an internal membrane layer, somewhat resembling the structure of several characterized virus groups, including tectiviruses (Bamford et al., 2005; Fauquet et al., 2005; Jäälinoja et al., 2008). A 3D model of SH1 has recently been published (Jäälinoja et al., 2008) and shows a dramatic array of surface spikes. The genome of SH1 is a GC-rich (68.4\%), linear dsDNA of $30898 \mathrm{bp}$, with terminal inverted repeat sequences (ITRs) and $5^{\prime}$ terminal proteins (Bamford et al., 2005; Porter et al., 2005; Porter \& Dyall-Smith, 2008). It is believed to be replicated by a protein-primed DNA polymerase, but the genome does not appear to encode any homologue of a known polymerase, and presumably uses a host enzyme.

In a previous study, the $\mathrm{SH} 1$ genome was sequenced, and particle lipids were analysed, capsid protein genes identified and bioinformatic analyses used to predict a total of 56 virus ORFs (Bamford et al., 2005). The dense packing and arrangement of these ORFs strongly suggested that they were transcribed as operons, and the authors proposed a minimum of four, and potentially six to eight, operons. In the current study, we have experimentally tested the proposed operon structure of halovirus $\mathrm{SH} 1$ by mapping the transcripts and promoters used at different times in the infection cycle, and used puromycin blockage of protein synthesis to detect regulation of virus gene expression.

\section{METHODS}

Media. Media relevant to this study were prepared according to established protocols, as described in the online resource The HaloHandbook (http://www.haloarchaea.com/resources/halohandbook $/)$. A $30 \%(\mathrm{w} / \mathrm{v})$ concentrated stock solution of artificial salt water (SW) containing (per litre): $240 \mathrm{~g} \mathrm{NaCl}, 30 \mathrm{~g} \mathrm{MgCl}_{2} \cdot 6 \mathrm{H}_{2} \mathrm{O}$, $35 \mathrm{~g} \mathrm{MgSO}_{4} .7 \mathrm{H}_{2} \mathrm{O}, 7 \mathrm{~g} \mathrm{KCl}, 0.5 \mathrm{~g} \mathrm{CaCl}_{2} \cdot 2 \mathrm{H}_{2} \mathrm{O}$, adjusted to $\mathrm{pH} 7.5$ using a small volume $(\sim 2 \mathrm{ml})$ of $1 \mathrm{M}$ Tris- $\mathrm{Cl}(\mathrm{pH} 7.5)$. From this stock, halovirus diluent (HVD) and modified growth medium (MGM) containing 18 or $23 \%(\mathrm{w} / \mathrm{v})$ SW were prepared as described previously (Nuttall \& Dyall-Smith, 1993; Porter et al., 2005).

Strains, growth conditions and virus purification. The haloarchaeon H. hispanica (ATCC 33960) (Juez et al., 1986) was grown in 18 or $23 \%(\mathrm{w} / \mathrm{v}) \mathrm{MGM}$, as described previously (Porter et al., 2005). Halovirus SH1 (GenBank accession no. AY950802) was propagated in $H$. hispanica cells, as previously described (Porter et al., 2005).

For virus purification, unlysed $H$. hispanica cells and cell debris were removed from the culture by low-speed centrifugation (Sorvall GSA; 6000 r.p.m., $30 \mathrm{~min}, 10^{\circ} \mathrm{C}$ ). Virus particles were then pelleted from the supernatant (Beckman SW28; 23000 r.p.m., 13 h, $10{ }^{\circ} \mathrm{C}$ ), onto a cushion of $30 \%(\mathrm{w} / \mathrm{v})$ sucrose, in HVD. The pellet was resuspended in HVD and purified by linear rate zonal 5-70\% (w/v) sucrose (in HVD) gradient centrifugation (Beckman SW28; 23000 r.p.m., 2 h, $\left.10{ }^{\circ} \mathrm{C}\right)$. The virus band was collected and recentrifuged to equilibrium in a solution containing $1.3 \mathrm{~g} \mathrm{CsCl} \mathrm{ml}^{-1}$, in HVD (Beckman 70Ti; 60000 r.p.m., $20 \mathrm{~h}, 10{ }^{\circ} \mathrm{C}$ ). The virus band was collected, diluted in HVD, and the virus pelleted (Beckman SW55; 35000 r.p.m., 75 min, $\left.10{ }^{\circ} \mathrm{C}\right)$. The virus pellet was resuspended in HVD.
Oligonucleotide primers. Oligonucleotide primers were purchased from GeneWorks. Oligonucleotide primers referred to in the text are listed in Table 1. A full list of the primers used in this study is provided in Supplementary Table S1 available with the online version of this paper.

Nucleic acid extractions. Virus DNA was extracted from purified virus preparations using SDS and proteinase $\mathrm{K}$, as described previously (Bath et al., 2006).

Infected-cell RNA was prepared as follows: Early exponential phase cells of $H$. hispanica were infected with $\mathrm{SH} 1$ at a m.o.i. of $50(1 \mathrm{~h}$, $37^{\circ} \mathrm{C}$ ). Under these conditions, the percentage of infected cells was expected to be $100 \%$ (Porter et al., 2005). Cells were washed of unadsorbed virus by three cycles of centrifugation and resuspension in $10 \mathrm{ml}$ fresh $18 \%(\mathrm{w} / \mathrm{v})$ MGM. After the final resuspension, cells were diluted in $100 \mathrm{ml}$ medium. In some cases, puromycin $(100 \mu \mathrm{g}$ $\mathrm{ml}^{-1}$; Sigma-Aldrich) was added to the infected cultures (Stolt \& Zillig, 1994). Cultures were then incubated at $37^{\circ} \mathrm{C}$, with slow shaking (100 r.p.m.), and $10 \mathrm{ml}$ samples were taken at hourly intervals and the cells were pelleted by centrifugation $(13000 \mathrm{~g}$, 2 min, $4{ }^{\circ} \mathrm{C}$ ). RNA was extracted using the RNeasy Mini kit (Qiagen), according to the manufacturer's specifications. To prevent DNA contamination, $10 \mu \mathrm{g}$ RNA was treated with $2 \mathrm{U}$ DNase I (RNasefree) (New England Biolabs) and 40 U Recombinant RNasin RNase Inhibitor (Promega) for $30 \mathrm{~min}$ at $37^{\circ} \mathrm{C}$. DNase I was inactivated at $75{ }^{\circ} \mathrm{C}$ for $10 \mathrm{~min}$.

RT-PCR. For first-strand cDNA synthesis, $0.5 \mu \mathrm{g}$ virus-specific primer was incubated with $\sim 1.5 \mu \mathrm{g}$ RNA at $70{ }^{\circ} \mathrm{C}$ for $5 \mathrm{~min}$, and was then chilled on ice for $5 \mathrm{~min}$. Reverse transcription was performed at $50{ }^{\circ} \mathrm{C}$ for $1 \mathrm{~h}$ using $30 \mathrm{U}$ AMV reverse transcriptase, with $40 \mathrm{U}$ Recombinant RNasin RNase Inhibitor and $1 \mathrm{mM}$ dNTPs (Promega). cDNA was purified using the QIAquick PCR Purification kit (Qiagen), and was resuspended in $30 \mu$ RNase-free $\mathrm{H}_{2} \mathrm{O}$.

A $3 \mu \mathrm{l}$ volume of the cDNA preparation was used as template for PCR using GoTaq Green Master Mix (Promega), according to the manufacturer's specifications. Template was denatured at $95{ }^{\circ} \mathrm{C}$ for $5 \mathrm{~min}$; followed by $25-35$ cycles of denaturation at $95{ }^{\circ} \mathrm{C}$ for $1 \mathrm{~min}$, annealing for $30 \mathrm{~s}$, and extension at $72{ }^{\circ} \mathrm{C}$ for $30 \mathrm{~s}$; and a final extension at $72{ }^{\circ} \mathrm{C}$ for $10 \mathrm{~min}$. cDNA levels were compared by dilution of the template, followed by 25 cycles of amplification.

A number of controls were performed to ensure the accuracy of the RT-PCR method. To avoid mis-priming on SH1 RNA during cDNA synthesis, primer sequences were first examined in silico against the SH1 genome sequence using the program AmplifX V1.4.0 (http:// ifrjr.nord.univ-mrs.fr/AmplifX?lang=en). For each experiment, three specific control reactions were included. First, a positive control to show the PCR components were functioning. This had the same additions, except that the template was SH1 DNA. Second, to check for mis-priming on host cell cDNA (that may have been synthesized during reverse-transcription), SH1-specific PCRs were performed on cDNA made from reverse-transcribed, uninfected H. hispanica RNA (using the same $\mathrm{SH} 1$-specific primers). This was a negative control. Third, a control for contamination by SH1 DNA used a template of RNA extracted from SH1-infected H. hispanica, but which had not undergone reverse transcription (negative control).

Additional controls were also performed. To confirm that the correct PCR products were generated, five randomly chosen products were sequenced. All gave the expected sequence (data not shown). To check that cDNA was not being randomly generated, a non-SH1specific primer, 1RTF, was used to reverse transcribe cDNA from SH1-infected $H$. hispanica RNA. The cDNA was then screened with six randomly chosen SH1-specific PCRs. All screens produced no 
Table 1. Oligonucleotide primers used in this study

\begin{tabular}{|c|c|c|c|}
\hline Primer & Sequence $\left(5^{\prime}-3^{\prime}\right)$ & Location (nt) & Position \\
\hline $242 \mathrm{R}$ & GGGTATCTGTCTTAAAGG & $242-259 ; 30631-30648$ & ITR \\
\hline $665 \mathrm{R}$ & GTTTTGCCCAACTAATTGGG & $684-665$ & ORF 3 \\
\hline $935 \mathrm{R}$ & GACCACCTCGAACTCGTAG & $953-935$ & ORF 4 \\
\hline $3124 \mathrm{R}$ & GTGTGCGGCTTAGGGAACCG & $3143-3124$ & ORF 12 \\
\hline $3416 \mathrm{R}$ & GTCCTTCAACCGGAGCAGG & $3343-3416$ & ORF 13 \\
\hline $10471 \mathrm{~F}$ & TCGTCCTTCTCCAGTTCGTT & $10452-10471$ & ORF 21 \\
\hline $11387 \mathrm{~F}$ & GTCTTGTAATCGCCATGCGTAG & $11367-11387$ & ORF 22 \\
\hline $11438 \mathrm{R}$ & TCACCTCCCGATAGGAATTG & $11457-11438$ & ORF $23-22$ \\
\hline $11457 \mathrm{~F}$ & CAATTCCTATCGGGAGGTGA & $11438-11457$ & ORF $22-23$ \\
\hline $11637 \mathrm{R}$ & GTCGTTACGACTTGTGCG & $11654-11637$ & ORF 23 \\
\hline $11675 \mathrm{R}$ & TCCTTTCATCGAGATGTCCC & $11694-11675$ & ORF 23 \\
\hline $11694 \mathrm{~F}$ & GGGACATCTCGATGAAAGGA & $11675-11694$ & ORF 23 \\
\hline $12286 \mathrm{R}$ & AAGTCGGAAGTGTCGTCACC & $12305-12286$ & ORF 24 \\
\hline $13251 \mathrm{~F}$ & GAACTGGACCCGTTTCTTCA & $13232-13251$ & ORF 26 \\
\hline $13518 \mathrm{R}$ & CTGTGCTACCTGCATCCAGA & $13537-13518$ & ORF 27 \\
\hline $16585 \mathrm{~F}$ & GAGCGTCTGGCACATCTACA & $16566-16585$ & ORF 29 \\
\hline 17398R & GACGATAAGAAGGACGAGCG & $17417-17398$ & ORF 30 \\
\hline $17790 \mathrm{~F}$ & CCAGTTATCCGGGTCAGAGA & $17771-17790$ & ORF 31 \\
\hline $18012 \mathrm{R}$ & GTTCGTTACGTAGGCGTCCG & $18031-18012$ & ORF 32 \\
\hline $18128 \mathrm{R}$ & GCTGTTGCTGTACGGGTAGAG & $18148-18128$ & ORF 32 \\
\hline $19437 \mathrm{~F}$ & GTGGACGAGGACGGGTACTA & $19418-19437$ & ORF 33 \\
\hline 19786R & GACTTCCACGATACCGTCGTG & $19806-19786$ & ORF 34 \\
\hline $25874 \mathrm{~F}$ & GTCCACGACCTTCTTCCCCTG & $25854-25874$ & ORF 49 \\
\hline $26523 \mathrm{~F}$ & GATTCCGTACTGCCAGTG & $26506-26523$ & ORF 50.5 \\
\hline $26960 \mathrm{~F}$ & GAGACGCCGGGGTAGCCGTCG & $26940-26960$ & ORF 51 \\
\hline $27573 \mathrm{~F}$ & GGACACTCCCGGTCGAGG & $27556-27573$ & ORF 53 \\
\hline $27833 \mathrm{~F}$ & GTTGAAGACGAACGCTCCG & $27815-27833$ & ORF 54 \\
\hline $30390 \mathrm{~F}$ & GTACACGTCGCGGAGGGTCTG & $30370-30390$ & ORF 55 \\
\hline $1 \mathrm{RTF}$ & CGACAGTAGTGAGTGAG & $1871-1887^{\star}$ & \\
\hline bgalpEXT & GCCATCTGACTGATATCGGTCTCC & pTM24† & \\
\hline
\end{tabular}

${ }^{\star}$ Designed to target the HF2 genome sequence (GenBank accession no. AF222060).

$\nmid$ Refer to Supplementary Fig. S1. All primers except bgalpEXT and 1RTF are designed to target the SH1 genome sequence (GenBank accession no. AY950802).

product (data not shown). As an additional control to ensure that cDNA was not being randomly generated, reverse transcription of cDNA from SH1-infected $H$. hispanica RNA was performed with no primer. The cDNA was then screened with six randomly chosen SH1-specific PCRs. All screens produced no product (data not shown). Transcripts were numbered from left to right along the genome.

Primer extension assays. Primer extension was performed essentially as described by Ausubel et al. (1994). Primer $(30 \mu \mathrm{M})$ was labelled with $30 \mu \mathrm{Ci}(1.1 \mathrm{MBq})\left[\gamma^{32} \mathrm{P}\right] \mathrm{ATP}$ using $2 \mathrm{U} \mathrm{T} 4$ polynucleotide kinase (New England Biolabs). cDNA was synthesized from $\sim 10 \mu \mathrm{g}$ RNA using $15 \mu \mathrm{Ci}(0.55 \mathrm{MBq})$ labelled primer, as above. A reference ladder was synthesized from $~ 10 \mathrm{ng}$ pTM24 (sequence shown in Supplementary Fig. S1), using $30 \mu \mathrm{Ci}$ (1.1 MBq) labelled primer bgalpEXT. Samples were then precipitated and analysed on a $6 \%(\mathrm{w} / \mathrm{v})$ premixed acrylamide/bis/urea sequencing gel (Ambion). The gel was electrophoresed at $60 \mathrm{~W}$ and products were exposed to a phosphoimager plate overnight.

Bioinformatic analyses. In silico analysis for primer mis-priming was performed using AmplifX V1.4.0 (http://ifrjr.nord.univ-mrs.fr/ AmplifX?lang=en). Cumulative AT and GC skews were produced using the DNA Base Composition Analysis Tool (http://molbiol-tools.ca/ Jie_Zheng).

\section{RESULTS}

\section{Fine mapping of SH1 transcripts}

To determine the operon structure of SH1, cDNAs of specific virus transcripts were systematically sized and mapped to the virus genome using RT-PCR (see Methods). An example of this strategy, shown in Fig. 1, summarizes the results for transcript T5, covering ORFs 23-34, for which the genome annotation suggested that these ORFs were likely to be transcribed as one operon. A cDNA copy of the predicted mRNA was prepared using SH1-infected H. hispanica RNA as template, and primer 19786R, which is complementary to a sequence (nucleotides 1978619806 ) near the end of ORF 34 . After reverse transcription, the length of the resulting cDNA was established by successive PCRs that scanned from the primer site 


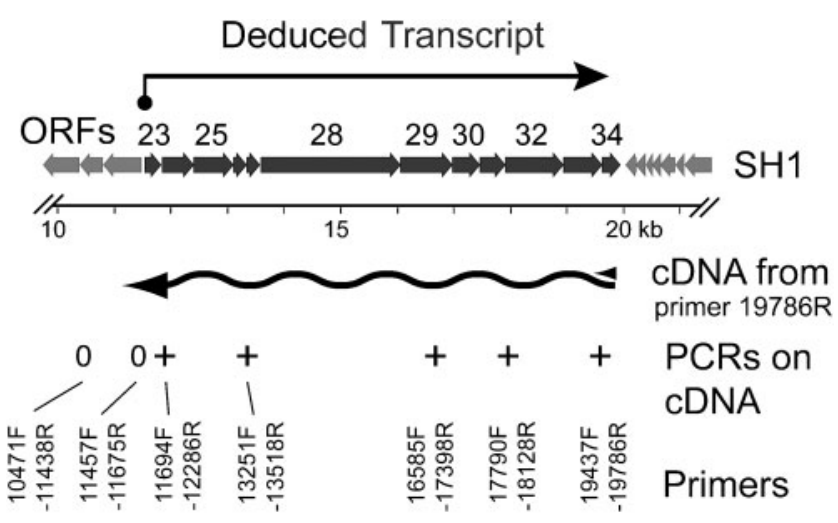

Fig. 1. $\mathrm{RT}-\mathrm{PCR}$ of $\mathrm{SH} 1$ transcription, covering the region of ORFs 23-34. Predicted ORFs, as proposed by Bamford et al. (2005), are numbered from left to right. Directions of ORFs are indicated by arrowheads. After the generation of the template using the $3^{\prime}-$ terminal primer $19786 \mathrm{R}$, this template was screened by PCR with the indicated primer pairs. The PCR products for each reaction, along with the control reactions, were separated on agarose gels, stained with ethidium bromide and photographed. 0 , Absence of transcript; + , presence of transcript. The inferred direction and length of the transcript is indicated. The transcription start site and the deduced transcript are indicated. Sizes in $\mathrm{kb}$ are given.

(nucleotide 19786) back towards the left end of the genome. As shown in Fig. 1, PCR products were detected up to nucleotide 11675 , but not at nucleotides $11438-$ 11694 , indicating that the $3^{\prime}$ end of the cDNA lay between ORFs 22 and 23. This location of the $5^{\prime}$ start of the transcript was consistent with the annotated ORF directions, and agreed with the primer extension data described below (nucleotide 11541 ). The $3^{\prime}$ end of this transcript was estimated using primers for cDNA synthesis at progressively more rightward positions. During the early and middle stages of $H$. hispanica infection (i.e. between 1 and $4 \mathrm{~h}$ post-infection; p.i.), transcript $\mathrm{T} 5$ is relatively short, terminating after ORF 34. However, late in infection (5-6 h p.i.) transcription extended beyond ORF 34 to at least nucleotide 26077 (within ORF 50). The extended form of transcript $\mathrm{T} 5$ was named $\mathrm{T} 5 \mathrm{e}$. The relative amounts of T5 and T5e were followed semiquantitatively (see Methods), and the levels of T5e were found to be approximately 10 -fold less than those of $\mathrm{T} 5$, indicating partial read-through at the $\mathrm{T} 5$ terminator.

In a similar way to transcript $\mathrm{T} 5$, the other $\mathrm{SH} 1$ transcripts produced during the early ( $1-2 \mathrm{~h}$ p.i.), middle (3-4 h p.i.) and late (5-6 h p.i.) stages of the infection cycle were mapped and sized, and the transcript levels on both DNA strands compared. The results are summarized in Fig. 2(c).

A total of seven major coding transcripts (designated T1T7), each encompassing several ORFs, were identified. Many transcripts were very long, and most were produced early in infection, with changes in the levels and lengths (see below) over the replication cycle. Transcript T4 encompassed ORFs 4-16, a length of approximately $7.4 \mathrm{~kb}$. The virus structural proteins are encoded by transcripts T2, T3, T4 (ORFs 13-22) and T5 (ORFs 2334 ), which are transcribed by closely spaced, outwardly directed promoters (Fig. 2; see below). T7 was the shortest transcript detected, encompassing ORFs $51-54(\sim 1.2 \mathrm{~kb})$. Transcript T6 was only observed late in infection, and included ORFs 35-50. Together, the identified transcripts cover nearly the entire $\mathrm{SH} 1$ genome. The cumulative AT-skew along the genome (Fig. 2b) shows a good correspondence between inflections in the plot (circled) and changes in transcriptional direction.

Transcripts T2, T3 and T4 were overlapping, beginning at different promoters (see below), but terminating at the same position after ORF 16. Semiquantitative assays (see Methods) and primer extension results (below) indicate that the three transcripts are produced at similar levels. They all include ORF 13, which encodes the largest structural virus protein.

Although repeatedly tested, transcription in the region covering ORF 55 (nucleotides 27880-30477) could not be detected. In addition to the RT-PCR protocol routinely used to screen for transcripts, the ORF 55 region was scrutinized in particular detail using several different cDNA synthesis primers and screening primer combinations, various time points for RNA extraction, and up to 35 cycles of PCR amplification. These assays all gave the appropriate control results and used the same RNA preparations that were used to map the transcripts shown in Fig. 2(c). Nevertheless, transcripts were not found for this ORF or complementary to this ORF, at any time between 1 and $6 \mathrm{~h}$ p.i.

The ITRs, i.e. prior to nucleotide 859 and after nucleotide 27883 , were also regions where no transcripts could be detected, on either strand, at any time between 1 and $6 \mathrm{~h}$ p.i.

\section{Extended viral transcripts}

Late in infection, transcriptional read-through of terminators produced longer transcripts. Since many SH1 operons face each other, many of the extended transcripts (denoted by an ' $e$ ' suffix, e.g. T2e) are complementary to the coding transcripts that they overlap (Fig. 2c). Excepting transcript T7, SH1 produced transcripts complementary to all of the coding mRNAs identified. The level of read-through varied between transcripts and at different times during infection. In some cases it was not possible to distinguish by RT-PCR the levels of shorter and longer transcripts originating from the same promoter. For example, T1 and T1e were expressed at similar levels early in infection (Fig. 2c), and may represent only the longer transcript (T1e), but late in infection there were $\sim 100$-fold higher levels of T1 relative to T1e, indicating that $\mathrm{T} 1$ termination was occurring, and both transcripts were produced. The situation was clearer in the case of T5/T5e, where T5 was produced early in infection, while transcript T5e was only produced late in infection, and at a $\sim 10$-fold 
(a) $\mathrm{SH} 1$ genome map
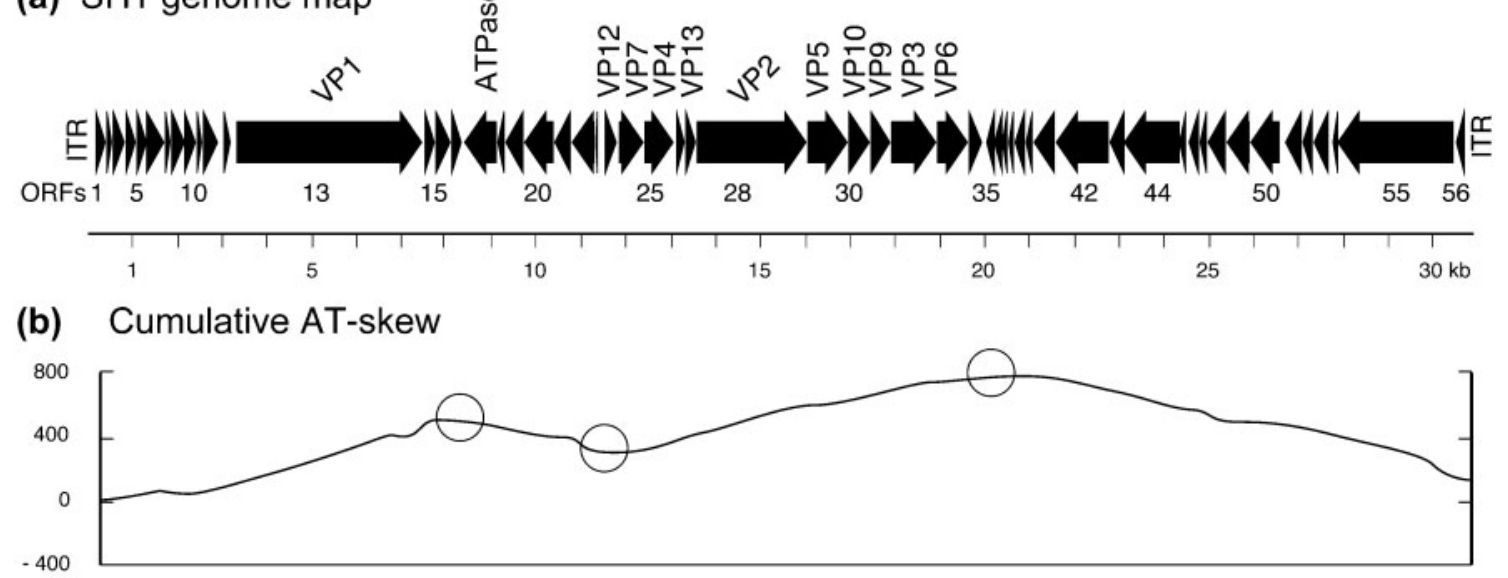

(c) Transcripts over the $H$. hispanica infection cycle

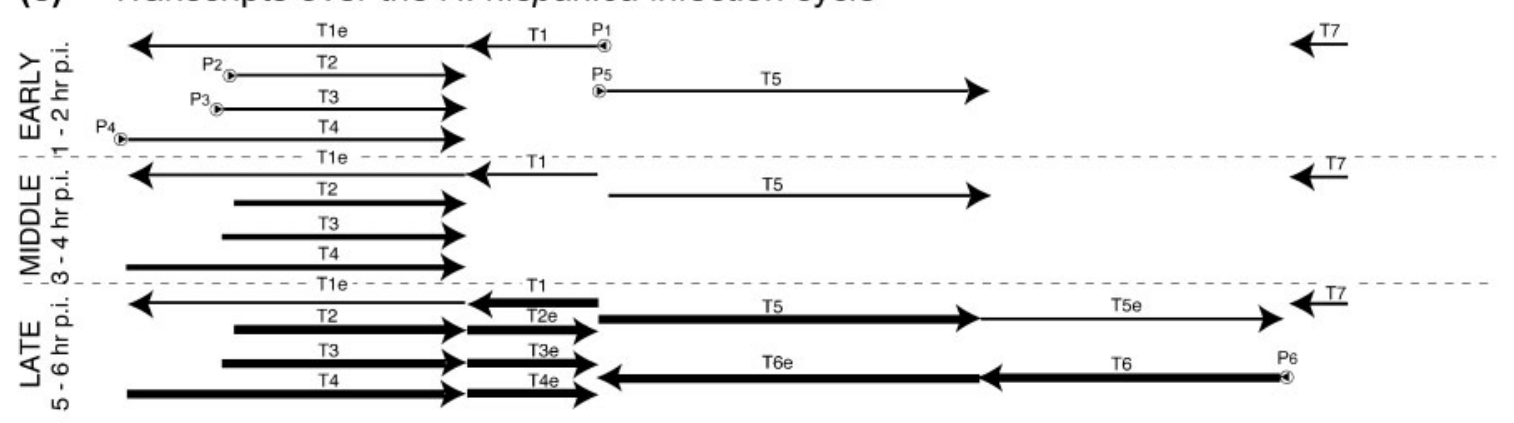

(d) Transcripts produced in the presence of puromycin

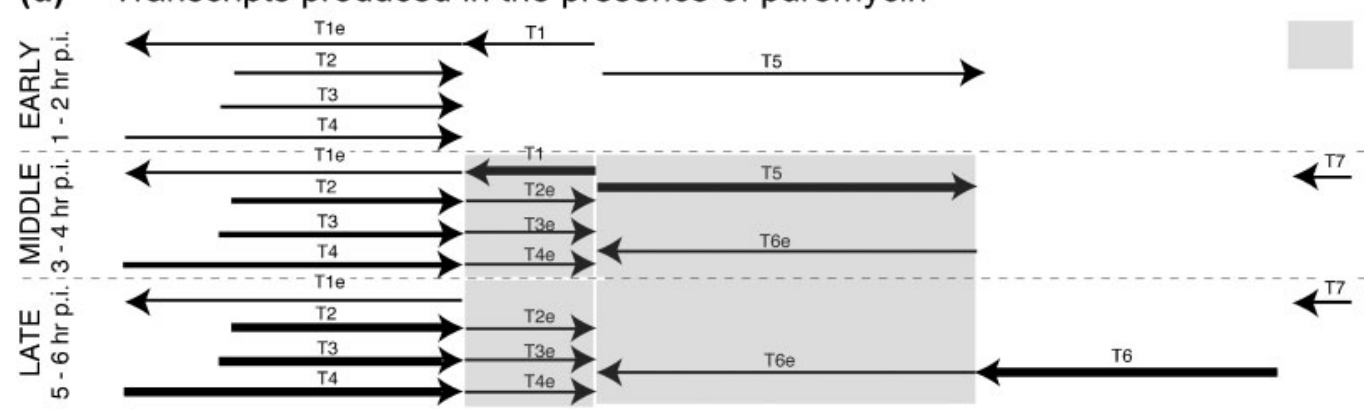

Fig. 2. Transcription of halovirus $\mathrm{SH} 1$. (a) $\mathrm{SH} 1$ genome map. Predicted ORFs are numbered from left to right. Directions of ORFs are indicated. ITRs and structural virion component VPs 1-7, 9, 10, 12 and 13 are indicated. The nomenclature of the predicted ORF gene assignments are as published by Bamford et al. (2005). Sizes in kb are given. (b) Cumulative AT-skew. Inflections are circled. (c) Transcripts over the H. hispanica SH1 infection cycle. The inferred direction and length of transcripts produced during early, middle and late infection of $H$. hispanica are indicated. Relative transcript levels are represented by varying line thickness. $\mathrm{P}$, transcription start site. (d) Transcripts produced in the presence of puromycin. The inferred direction and length of transcripts produced in the presence of puromycin are indicated. Relative transcript levels are represented by varying line thickness. Grey boxes indicate transcriptional changes compared with (c).

lower level compared with T5. The difference in timing and relative levels can be interpreted as weak read-through transcription of the T5 terminator to a more distal terminator at or near promoter P6.

Late in infection, transcripts T2e-T4e and T6e were produced at $\sim 10$-fold higher levels compared with the complementary transcripts that they overlap (Fig. 2c). As these transcripts would be partially or completely complementary (e.g. T1 and T2e; T5 and T6e), they could bind to form dsRNA, and so block translation. In this way, the extended transcripts may play a regulatory role in mRNA translation.

\section{Location of SH1 promoters by primer extension}

Using primer extension, the upstream regions of the previously predicted operons were examined for potential 


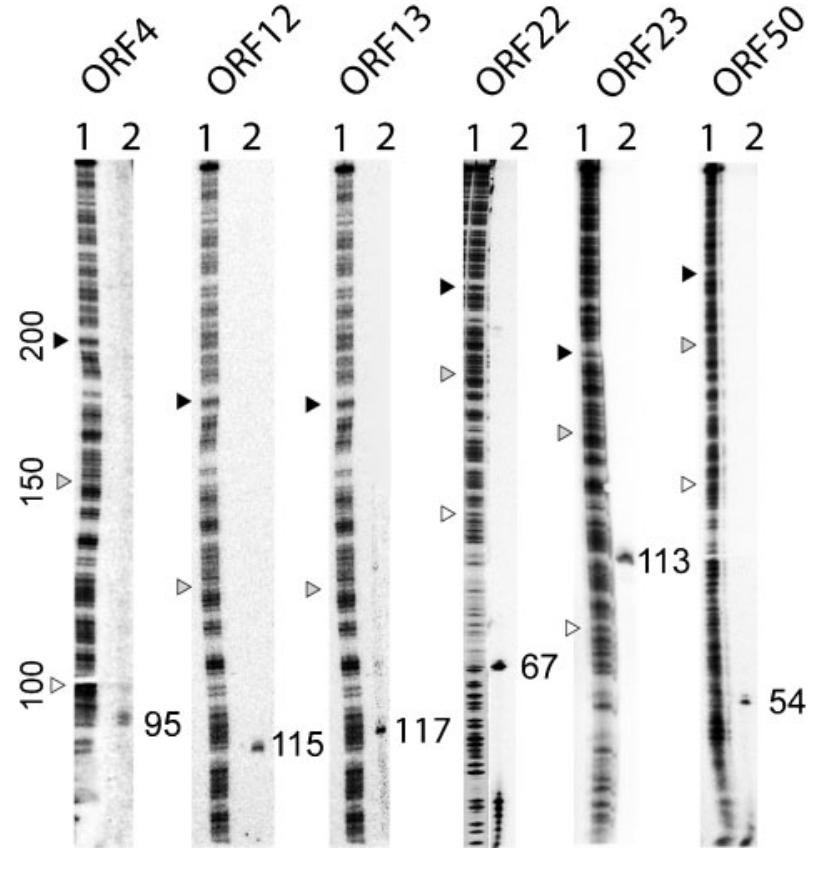

Fig. 3. Identification of $\mathrm{SH} 1$ transcriptional start sites. Using primer extension, the transcription start sites for SH1 ORFs 4, 12, 13, 22, 23 and 50 were mapped. Primers used for each experiment are given in Table 2. For each panel, lane 1 is a size ladder and lane 2 is the primer extension product. Ladder positions for 100,150 and $200 \mathrm{nt}$ are indicated at the left of each gel panel by triangles (open, grey and filled, respectively). The extension product lengths are indicated at the right edge of each gel panel. Sizes are in nt.

transcription start sites (Fig. 2a) (Bamford et al., 2005), i.e. upstream of ORFs $1,12,13,22,23,50,53,55$ and 56 . For these assays, infected cell RNA was used as template in reverse-transcriptase reactions containing labelled, virusspecific primers. The results are summarized in Fig. 3 and Table 2.

Transcription start sites were found in five of the nine regions predicted from the published ORF map, i.e. upstream of ORFs 12, 13, 22, 23 and 50 (Fig. 3). None was detected upstream of ORFs 1, 53, 55 and 56 (Table 2), which led to additional screening upstream of ORFs 2, 4, 32, 49, 51 and 54. As shown in Table 2, a start site near the beginning of ORF 4 (primer 935R) was mapped to nucleotide 858 , but the other five regions were negative. In summary, the mapped start sites corresponded closely to the $5^{\prime}$ ends of transcripts mapped by RT-PCR, while the lack of detectable start sites upstream of ORFs 1, 2, 55 and 56 was consistent with the RT-PCR data, which did not show transcription across ORFs 1-3, 55 and 56 (above, Fig. 2c). The primer extensions for transcripts $\mathrm{T} 2, \mathrm{~T} 3$ and $\mathrm{T} 4$ were all performed on the same RNA preparation, at the same time, and run on the same gel (Fig. 3). The results indicate that all three promoters $(\mathrm{P} 2, \mathrm{P} 3$ and $\mathrm{P} 4)$ are
Table 2. Summary of primer extension results using infected cell RNA

\begin{tabular}{|c|c|c|c|}
\hline ORF & Promoter & Primer & Primer extension product \\
\hline ORF 1 & & $242 \mathrm{R}$ & - \\
\hline ORF 3 & & $665 \mathrm{R}$ & - \\
\hline ORF 4 & P4 & $935 \mathrm{R}$ & Product of 95 nt (nucleotide 858) \\
\hline ORF 12 & P3 & $3124 \mathrm{R}$ & Product of 115 nt (nucleotide 3028) \\
\hline ORF 13 & P2 & $3416 \mathrm{R}$ & Product of 117 nt (nucleotide 3317) \\
\hline ORF 22 & P1 & $11387 \mathrm{~F}$ & Product of 67 nt (nucleotide 11434 ) \\
\hline ORF 23 & P5 & $11637 \mathrm{R}$ & $\begin{array}{l}\text { Product of } 113 \text { nt (nucleotide } \\
\text { 11541) }\end{array}$ \\
\hline ORF 32 & & $18012 \mathrm{R}$ & - \\
\hline ORF 49 & & $25874 \mathrm{~F}$ & - \\
\hline ORF 50 & P6 & $26523 \mathrm{~F}$ & Product of 54 nt (nucleotide 26560) \\
\hline ORF 51 & & $26960 \mathrm{~F}$ & - \\
\hline ORF 53 & & $27573 \mathrm{~F}$ & - \\
\hline ORF 54 & & $27833 \mathrm{~F}$ & - \\
\hline ORF 55 & & $30390 \mathrm{~F}$ & - \\
\hline ORF 56 & & $242 \mathrm{R}$ & - \\
\hline
\end{tabular}

utilized, and that the levels of transcripts $\mathrm{T} 2$ and $\mathrm{T} 3 \mathrm{are}$ approximately equal, while the levels of T4 are slightly less.

\section{SH1 promoters and repeated sequence elements nearby}

The regions upstream of the mapped $5^{\prime}$ transcription start sites are shown in Fig. 4. For ORF 4, there may be an alternative transcription initiation site. Likely promoter elements are indicated and, for comparison, the consensus haloarchaeal promoter sequence is given below. Potential TATA box motifs can be seen for the promoters upstream of ORFs 12, 13, 22 and 23, although in some motifs only five convincing bases can be identified. TATA boxes are difficult to identify upstream of the start sites near ORFs 4 or 50.5, although both of these promoters contain a novel element $(\mathrm{WW})$ at $-11 /-10$, as noted by Brenneis et al. (2007).

Start codons for ORFs $12,13,22$ and 23 are only $0-5 \mathrm{nt}$ from their respective transcription start sites, and the mRNAs for these ORFs are either leaderless or too short to contain a Shine-Dalgarno sequence.

The sequences around the major virus promoters were examined for repeated sequences that may represent factor binding sites regulating promoter activity. The reversecomplement of the sequence CCACCAATTCCTA occurs twice, $30 \mathrm{nt}$ apart, on either side of promoter P1 between ORFs 22 and 23 (overlined in Fig. 4). There is an additional imperfect repeat, CCACCAACTCC, $29 \mathrm{nt}$ leftward of the first copy, on the opposite strand (nucleotides 1139311 403) (SH1 GenBank accession no. AY950802). Promoter P3 (between ORFs 11 and 12) has a similar shorter sequence, CCACCAATT, nearby (underlined in Fig. 4); 


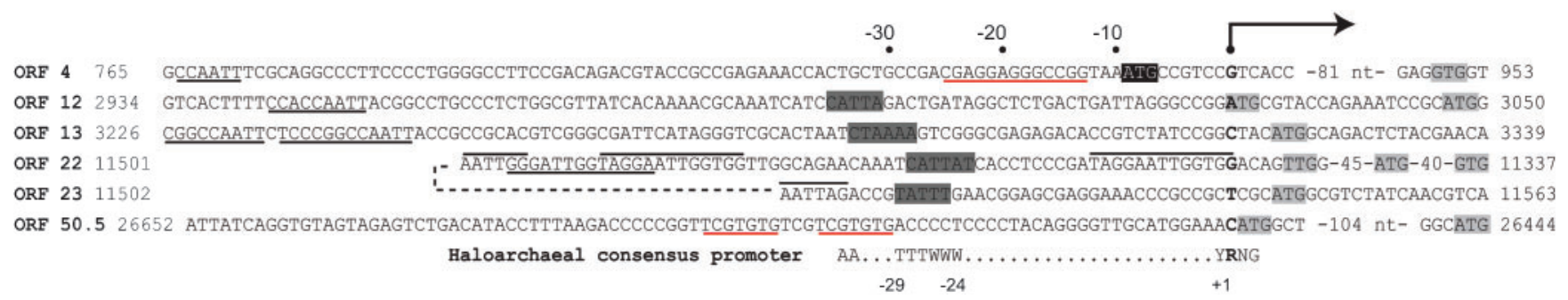

Fig. 4. Alignment of the promoter regions of halovirus SH1. The mapped transcription start sites are shown in bold type. The predicted start codons are shaded in light grey. The start codons predicted in silico (Bamford et al., 2005) are highlighted in black. The predicted TATA boxes are shown in dark grey. Common repeat regions and regions of complementary sequence are underlined and overlined, respectively. Sizes in nt are given. The SH1 GenBank accession number is AY950802.

and promoter P2 (between ORFs 12 and 13) is downstream of two directly repeated copies of the sequence TCCCGGCCAATT. All of these repeats contain the same hexameric motif CCAATT (bold type above), which is also present 60 nt upstream of the P4 promoter. This motif has a highly uneven distribution along the $\mathrm{SH} 1$ genome, being found 14 times between nucleotides 1 and 11474 but only once thereafter (at nucleotide 24391).

The sequence CGACGAGGAGGGCCGG occurs close to the $\mathrm{P} 4$ promoter $(-13$ to -25 in Fig. 4$)$ and is repeated $131 \mathrm{nt}$ downstream, while an imperfect copy appears $94 \mathrm{nt}$ upstream. Near promoter P6, upstream of ORF 50.5, are two closely spaced direct repeats of the sequence CACACGA (underlined in Fig. 4), flanked by poly-G tracts. The latter sequence motif also occurs singly within ORFs 13, 20 and 33. While no promoter was identified for transcript T7, immediately upstream of ORF 54 is an inverted repeat sequence that could form a strong potential hairpin-loop, CGGTCCGCCTCGTCGTCCAGGCGGGCCG. A transcript for ORF 55 was not detected, but upstream of the start codon was the sequence GCGGGCGGT, repeated twice between nucleotides 30555 and 30573, and not found elsewhere in the genome.

\section{Reannotation of the SH1 genome}

The results of this study can be used to refine the previously published annotation of the SH1 genome (Bamford et al., 2005). Transcription across ORFs 1 and 56 was not detectable. These ORFs occur within the ITR sequences, a very uncommon location for protein-coding regions in the genomes of other protein-primed viruses (Supplementary Table S2). In addition, the first 48 aa of the predicted proteins are encoded by the ITR sequences, and are identical, but afterwards they differ significantly in length and sequence. Finally, the isoelectric points (IEPs) of their predicted protein products are very high $(>11)$ compared with most haloarchaeal proteins, which average around 5 (Baliga et al., 2004; Bolhuis et al., 2006; Falb et al., 2005; Ng et al., 2000). Together, these features indicate that ORFs 1 and 56 are unlikely to be used to encode SH1 proteins. Transcription across ORFs 2 and 3 was also not detected and their predicted proteins have very high IEPs $(>12)$.

RT-PCR determined the $5^{\prime}$ end of the long T4 transcript to be near the start of ORF 4, and primer extension on T4 mRNA refined this to a position occurring a few codons within ORF 4. To accommodate the shorter than expected transcript, the next most likely start codon (in the same reading frame) would be a GUG, $92 \mathrm{nt}$ downstream at nucleotides 948-950, a position that occurs at the end of a predicted strong stem-loop structure.

ORF 12 begins $19 \mathrm{nt}$ downstream of the transcription start point determined in this study, and while this arrangement is compatible with the published annotation, the first three bases of the transcript form an AUG start codon for an ORF (nucleotides 3028-3180) that largely overlaps ORF 12 but in a different reading frame. This alternative ORF has a calculated IEP of 5.32, similar to the average for haloarchaeal proteins, while the IEP of the ORF 12 protein is very high $(\mathrm{IEP}=11.7)$. Which of these two ORFs is utilized by $\mathrm{SH} 1$ will need to be determined.

The transcriptional start site of ORF 22 was determined to be downstream of the annotated start codon, making this ORF shorter than previously predicted. It may start at a downstream GUG start codon beginning at nucleotide 11339, or perhaps use a UUG start codon beginning at nucleotide 11429 (Fig. 4).

The transcriptional start site for ORF 50 was located $42 \mathrm{nt}$ downstream of the annotated GUG translation start codon. Just $1 \mathrm{nt}$ from the $5^{\prime}$ end of the transcript is an AUG codon that begins a new ORF (ORF 50.5, nucleotides 2655926443), which terminates just past an AUG start codon for a now shortened version of ORF 50 (ORF 50s, nucleotides 26446-25 937). Within ORF50.5, there are no potential start codons in-frame with ORF 50 until nucleotide 25937 , so the arrangement of ORF 50.5-ORF 50s appears the most likely.

SH1 ORF 55 is intriguing, as it appears to be a legitimate coding ORF yet transcription across it was not detected. 
While the predicted protein shows no sequence similarity to known or hypothetical protein sequences, it is long (865 aa), has a low calculated IEP that is characteristic of haloarchaeal proteins, and is conserved in a related virus (K. Porter and M. L. Dyall-Smith, unpublished data). The cumulative GC skew plot of the genome is also consistent with this ORF being transcribed. Perhaps ORF 55 is transcribed only under specific conditions, or at a very early time in infection, or the mRNA has a very short halflife.

\section{The influence of puromycin on virus transcription}

The antibiotic puromycin prevents protein synthesis by binding to ribosomes, and can be used to show whether the transcription of virus genes is dependent on the translated product(s) of other genes (Azzam \& Algranati, 1973; Matsunaga et al., 2001). It has been used to study halovirus $\varphi \mathrm{H}$ gene expression (Gropp et al., 1989, 1992). As shown in Fig. 2(d), puromycin blocked the late expression of transcripts $\mathrm{T} 1$ and $\mathrm{T} 5$, while upregulating their transcription during the mid-phase of infection. Levels of T2e-T4e and T6e were lower and occurred earlier, while the appearance of T7 was delayed. The blocking of transcript T5 late in infection also resulted in the absence of transcript T5e, but this was not the case with $\mathrm{T} 1$ and T1e, for which the counter-transcript covering ORFs 4-16 was detected (T1e). This may indicate the use of an additional promoter. There was no effect on the expression of transcripts T2, T3, T4 or T6.

\section{DISCUSSION}

The SH1 genome was sequenced in 2005 , and proposed to contain a minimum of four, and potentially six to eight, functional operons (Bamford et al., 2005). In the present study, the protein-coding ORFs of SH1 were indeed found to be transcribed as long, polycistronic mRNAs that cover most of the genome. Excluding the 'extended' transcripts, there are seven major mRNAs that contain between 4 and 16 ORFs each, largely matching the operon predictions of Bamford et al. (2005). There were two distinct phases of transcription, early-middle and late, as well as changes in relative levels over the course of infection. Early/late transcription, with no distinctive middle phase, has been observed in other viruses, including archaeal viruses SIRV1 and SIRV2 (Kessler et al., 2004).

Surprisingly, transcripts encoding the capsid proteins were synthesized from the earliest period examined, 1 h p.i., and increased in relative amounts over the infection cycle. The structural protein genes and the putative packaging ATPase (ORF 17) were most highly transcribed late in infection (5$6 \mathrm{~h}$ p.i.), when capsid assembly and genome packaging would be expected to be maximal. Three promoters were located over the region of ORFs 4-16, producing overlapping transcripts that all terminated just after ORF 16. All three transcripts included ORF 13, encoding viral protein (VP)1, the largest capsid protein. The thermophilic archaeal virus SSV1 shows a similar behaviour, with many genes being transcribed as operons from single $5^{\prime}$ start sites, but with terminator read-through resulting in the formation of several RNA species (Fröls et al., 2007; Reiter et al., 1987). The archaeal satellite virus pSSVx also utilizes transcriptional read-through of terminators (Contursi et al., 2007).

Transcript T6 was the only late SH1 transcript, appearing after $4 \mathrm{~h}$ p.i. In many bacteriophages, the late genes encode virus structural proteins, but T6, encompassing ORFs 3550.5 (see below), includes no known structural proteins, and only one ORF that shows significant similarity to a known sequence. The ORF 48 predicted protein is similar in size and sequence to halovirus $\varphi \mathrm{Ch} 1$ protein $\mathrm{p} 72$ (GenBank accession no. AAM88745), although the function of the latter is unknown. The putative promoter for T6 does not display a consensus TATA motif, but there are repeat elements nearby that may be involved in late activation. There are reported examples of archaeal viruses that use protein activators of both viral (Iro et al., 2007) and host cell origin (Kessler et al., 2006).

An extraordinary feature of SH1 transcription was the degree of transcription from the non-coding strand. This is particularly evident late in infection, when many transcripts read-through their early phase terminators to more distal sites, resulting in counter-transcripts for most of the coding transcripts. These counter-transcripts do not contain convincing ORFs and are unlikely to encode functional proteins, but may be a form of translational regulation. In some cases the levels of counter-transcripts were low relative to their cognate coding transcripts, and any complementary binding between them would not be expected to be significant. The detection of such transcripts may be a reflection of the sensitive nature of RT-PCR. However, late in infection (5-6 h p.i.), not only were the levels of $\mathrm{T} 1$ and $\mathrm{T} 5$ high, but so were those of their counter-transcripts. The stability and abundance of these transcripts, as well as the potential interactions between complementary virus transcripts and their effects on $\mathrm{SH} 1$ gene expression, are areas for future study. The regulatory effects of dsRNA and interference RNA in halovirus replication have been well documented. Earlier work with halovirus $\varphi \mathrm{H}$ has demonstrated the regulatory role of antisense RNA along with processing of dsRNA by a novel and previously unknown RNase of haloarchaea (Stolt \& Zillig, 1993). Archaeal satellite virus pSSVx also makes use of anti-sense RNAs (Contursi et al., 2007). In the latter example, translation is blocked by modifying the $5^{\prime}$ ends of mRNAs, although even if dsRNase processing alters the $3^{\prime}$ untranslated regions of viral mRNAs, alterations in mRNA stability could still affect translation (Brenneis et al., 2007).

SH1 promoters P1 and P5 are $49 \mathrm{nt}$ apart and arranged back-to-back, an organizational pattern that is frequently observed in virus genomes and commonly used to ensure that the activities of nearby promoters, such as in 
switching between lytic and temperate programmes of gene expression, are co-regulated (Beck \& Warren, 1988). In such cases, the intergenic regions often bind regulatory proteins that alter the activity of one or both promoters. For example, in phage $\varphi 29$ the outward-facing promoters $\mathrm{A} 3$ and $\mathrm{A} 2(\mathrm{~b}, \mathrm{c})$ are $219 \mathrm{nt}$ distant, and are regulated cooperatively by virus proteins $\mathrm{p} 4$ and $\mathrm{p} 6$, which bind at four sites between them and activate promoter A3 while repressing A2(b,c) (Badia et al., 2006; Camacho \& Salas, 2001; Meijer et al., 2001). In the temperate halovirus $\varphi \mathrm{H}$, the back-to-back rep gene and T4 promoters are much closer, being just 63 nt apart. Here, rep expression was shown to be repressed directly by transcription from the T4 promoter, without the participation of regulatory virus proteins (Stolt \& Zillig, 1994). The RT-PCR results of the present study indicate that even though the P1 and P5 promoters are even more closely spaced than in the $\varphi \mathrm{H}$ example, they do not appear to interfere with each other, as their activities parallel each other, with transcription rising at the same time from low to high levels late in infection. The role of the sequence repeats near these promoters remains to be determined.

Puromycin blockage of protein synthesis altered the timing of some early-middle $\mathrm{SH} 1$ transcripts, advancing transcripts T1, T5, T2e-T4e and T6e, while delaying T7. The behaviour of T2e-T4e may be explained by antitermination of the T2-T4 transcripts. Others were unaffected (T2-T4), as was the major late transcript T6. The unaltered transcription pattern of $\mathrm{T} 6$ suggests that protein synthesis during infection is not required for regulation of its promoter (P6). Other effects of puromycin were the reduced or undetectable levels of specific transcripts late in infection, such as $\mathrm{T} 1$ and $\mathrm{T} 5$, as well as the extended transcripts T2e-T6e. As the extended transcripts $\mathrm{T} 2-\mathrm{T} 4 \mathrm{e}$ and T6e were unaffected, although their 'parent' transcripts (T2-T4 and T6) were not, this suggests that they may have a separate promoter, rather than being extensions of the original transcripts. The changes seen in the overall pattern of transcription were complex, suggesting that two or more interacting regulatory mechanisms are involved.

In summary, the genes of halovirus $\mathrm{SH} 1$ are organized into a relatively small number of operons with tightly regulated promoters. Late in infection, transcription is characterized by extensive counter-transcription that may influence the translation of mRNAs. More detailed studies of gene regulation in this virus will not only allow us to improve our understanding and annotation of the $\mathrm{SH} 1$ genome, but also allow a deeper understanding of archaeal (particularly haloarchaeal) transcriptional behaviour.

\section{ACKNOWLEDGEMENTS}

The support of the Department of Microbiology and Immunology (University of Melbourne) is greatly appreciated. B.E.R. was supported by Melbourne Research Scholarships. K. P. was supported by an Australian Postgraduate Award.

\section{REFERENCES}

Ackermann, H. W. (2007). 5500 Phages examined in the electron microscope. Arch Virol 152, 227-243.

Ausubel, F. M., Brent, R., Kingston, R. E., Moore, D. D., Seidman, J. G., Smith, J. A. \& Struhl, K. (1994). Current Protocols in Molecular Biology. New York: John Wiley and Sons.

Azzam, M. E. \& Algranati, I. D. (1973). Mechanism of puromycin action: fate of ribosomes after release of nascent protein chains from polysomes. Proc Natl Acad Sci U S A 70, 3866-3869.

Badia, D., Camacho, A., Perez-Lago, L., Escandon, C., Salas, M. \& Coll, M. (2006). The structure of phage $\phi 29$ transcription regulator p4-DNA complex reveals an N-hook motif for DNA. Mol Cell 22, 7381.

Baliga, N. S., Bonneau, R., Facciotti, M. T., Pan, M., Glusman, G., Deutsch, E. W., Shannon, P., Chiu, Y., Weng, R. S. \& other authors (2004). Genome sequence of Haloarcula marismortui: a halophilic archaeon from the Dead Sea. Genome Res 14, 2221-2234.

Bamford, D. H., Ravantti, J. J., Rönnholm, G., Laurinavičius, S., Kukkaro, P., Dyall-Smith, M., Somerharju, P., Kalkkinen, N. \& Bamford, J. K. (2005). Constituents of SH1, a novel lipid-containing virus infecting the halophilic euryarchaeon Haloarcula hispanica. $J$ Virol 79, 9097-9107.

Bath, C., Cukalac, T., Porter, K. \& Dyall-Smith, M. (2006). His1 and His2 are distantly related, spindle-shaped haloviruses belonging to the novel virus group, Salterprovirus. Virology 350, 228-239.

Beck, C. F. \& Warren, R. A. (1988). Divergent promoters, a common form of gene organization. Microbiol Rev 52, 318-326.

Benlloch, S., López-López, A., Casamayor, E. O., Øvreås, L., Goddard, V., Daae, F. L., Smerdon, G., Massana, R., Joint, I. \& other authors (2002). Prokaryotic genetic diversity throughout the salinity gradient of a coastal solar saltern. Environ Microbiol 4, 349-360.

Bolhuis, H., Palm, P., Wende, A., Falb, M., Rampp, M., RodriguezValera, F., Pfeiffer, F. \& Oesterhelt, D. (2006). The genome of the square archaeon Haloquadratum walsbyi: life at the limits of water activity. BMC Genomics 7, 169.

Bouvier, T. \& del Giorgio, P. (2007). Key role of selective viralinduced mortality in determining marine bacterial community composition. Environ Microbiol 9, 287-297.

Brenneis, M., Hering, O., Lange, C. \& Soppa, J. (2007). Experimental characterization of cis-acting elements important for translation and transcription in halophilic Archaea. PLoS Genet 3, e229.

Burns, D. G., Camakaris, H. M., Janssen, P. H. \& Dyall-Smith, M. L. (2004). Combined use of cultivation-dependent and cultivationindependent methods indicates that members of most haloarchaeal groups in an Australian crystallizer pond are cultivable. Appl Environ Microbiol 70, 5258-5265.

Camacho, A. \& Salas, M. (2001). Mechanism for the switch of $\phi 6$ DNA early to late transcription by regulatory protein $\mathrm{p} 4$ and histonelike protein p6. EMBO J 20, 6060-6070.

Cline, S. W. \& Doolittle, W. F. (1992). Transformation of members of the genus Haloarcula with shuttle vectors based on Halobacterium halobium and Haloferax volcanii plasmid replicons. J Bacteriol 174, 1076-1080.

Contursi, P., Cannio, R., Prato, S., She, Q., Rossi, M. \& Bartolucci, S. (2007). Transcriptional analysis of the genetic element pSSVx: differential and temporal regulation of gene expression reveals correlation between transcription and replication. J Bacteriol 189, 6339-6350.

Dyall-Smith, M., Tang, S. L. \& Bath, C. (2003). Haloarchaeal viruses: how diverse are they? Res Microbiol 154, 309-313. 
Falb, M., Pfeiffer, F., Palm, P., Rodewald, K., Hickmann, V., Tittor, J. \& Oesterhelt, D. (2005). Living with two extremes: conclusions from the genome sequence of Natronomonas pharaonis. Genome Res 15, $1336-1343$.

Fauquet, C. M., Mayo, M. A., Maniloff, J., Desselberger, U. \& Ball, L. A. (2005). Virus Taxonomy, VIIIth Report of the ICTV. London: Elsevier/ Academic Press.

Fröls, S., Gordon, P. M., Panlilio, M. A., Schleper, C. \& Sensen, C. W. (2007). Elucidating the transcription cycle of the UV-inducible hyperthermophilic archaeal virus SSV1 by DNA microarrays. Virology 365, 48-59.

Gropp, F., Palm, P. \& Zillig, W. (1989). Expression and regulation of Halobacterium halobium phage $\phi \mathrm{H}$ genes. Can J Microbiol 35, 182-188.

Gropp, F., Grampp, B., Stolt, P., Palm, P. \& Zillig, W. (1992). The immunity-conferring plasmid $\mathrm{p} \phi \mathrm{HL}$ from the Halobacterium salinarium phage $\phi \mathrm{H}$ : nucleotide sequence and transcription. Virology 190, 45-54.

Guixa-Boixareu, N., Calderón-Paz, J. I., Heldal, M., Bratbak, G. \& Pedrós-Alió, C. (1996). Viral lysis and bacterivory as prokaryotic loss factors along a salinity gradient. Aquat Microb Ecol 11, 215-227.

Hendrix, R. W. (2002). Bacteriophages: evolution of the majority. Theor Popul Biol 61, 471-480.

Hendrix, R. W., Smith, M. C., Burns, R. N., Ford, M. E. \& Hatfull, G. F. (1999). Evolutionary relationships among diverse bacteriophages and prophages: all the world's a phage. Proc Natl Acad Sci U S A 96, 21922197.

Iro, M., Klein, R., Galos, B., Baranyi, U., Rossler, N. \& Witte, A. (2007). The lysogenic region of virus $\varphi$ Ch1: identification of a repressoroperator system and determination of its activity in halophilic Archaea. Extremophiles 11, 383-396.

Jäälinoja, H. T., Roine, E., Laurinmäki, P., Kivelä, H. M., Bamford, D. H. \& Butcher, S. J. (2008). Structure and host-cell interaction of SH1, a membrane-containing, halophilic euryarchaeal virus. Proc Natl Acad Sci U S A 105, 8008-8013.

Juez, G., Rodriguez-Valera, F., Ventosa, A. \& Kushner, D. J. (1986). Haloarcula hispanica spec. nov. and Haloferax gibbonsii spec. nov., two new species of extremely halophilic archaebacteria. Syst Appl Microbiol 8, 75-79.

Kessler, A., Brinkman, A. B., van der Oost, J. \& Prangishvili, D. (2004), Transcription of the rod-shaped viruses SIRV1 and SIRV2 of the hyperthermophilic archaeon Sulfolobus. J Bacteriol 186, 7745-7753.

Kessler, A., Sezonov, G., Guijarro, J. I., Desnoues, N., Rose, T., Delepierre, M., Bell, S. D. \& Prangishvili, D. (2006). A novel archaeal regulatory protein, Stal, activates transcription from viral promoters. Nucleic Acids Res 34, 4837-4845.

Matsunaga, F., Forterre, P., Ishino, Y. \& Myllykallio, H. (2001). In vivo interactions of archaeal $\mathrm{Cdc} 6 / \mathrm{Orcl}$ and minichromosome maintenance proteins with the replication origin. Proc Natl Acad Sci U S A 98, 11152-11157.

Meijer, W. J., Horcajadas, J. A. \& Salas, M. (2001). $\varphi 29$ family of phages. Microbiol Mol Biol Rev 65, 261-287.

Ng, W. V., Kennedy, S. P., Mahairas, G. G., Berquist, B., Pan, M., Shukla, H. D., Lasky, S. R., Baliga, N. S., Thorsson, V. \& other authors (2000). Genome sequence of Halobacterium species NRC-1. Proc Natl Acad Sci U S A 97, 12176-12181.

Nuttall, S. D. \& Dyall-Smith, M. L. (1993). HF1 and HF2: novel bacteriophages of halophilic archaea. Virology 197, 678-684.

Oren, A., Bratbak, G. \& Heldal, M. (1997). Occurrence of virus-like particles in the Dead Sea. Extremophiles 1, 143-149.

Porter, K. \& Dyall-Smith, M. L. (2008). Transfection of haloarchaea by the DNAs of spindle and round haloviruses and the use of transposon mutagenesis to identify non-essential regions. Molecular Microbiology (in press).

Porter, K., Kukkaro, P., Bamford, J. K., Bath, C., Kivelä, H. M., DyallSmith, M. L. \& Bamford, D. H. (2005). SH1: a novel, spherical halovirus isolated from an Australian hypersaline lake. Virology 335, 22-33.

Prangishvili, D., Forterre, P. \& Garrett, R. A. (2006). Viruses of the Archaea: a unifying view. Nat Rev Microbiol 4, 837-848.

Reiter, W. D., Palm, P., Yeats, S. \& Zillig, W. (1987). Gene expression in archaebacteria: physical mapping of constitutive and UV-inducible transcripts from the Sulfolobus virus-like particle SSV1. Mol Gen Genet 209, 270-275.

Stolt, P. \& Zillig, W. (1993). Antisense RNA mediates transcriptional processing in an archaebacterium, indicating a novel kind of RNase activity. Mol Microbiol 7, 875-882.

Stolt, P. \& Zillig, W. (1994). Transcription of the halophage $\varphi \mathrm{H}$ repressor gene is abolished by transcription from an inversely oriented lytic promoter. FEBS Lett 344, 125-128.

Weinbauer, M. G. (2004). Ecology of prokaryotic viruses. FEMS Microbiol Rev 28, 127-181.

Woods, W. G., Ngui, K. \& Dyall-Smith, M. (1999). An improved transposon for the halophilic archaeon Haloarcula hispanica. J Bacteriol 181, 7140-7142.

Edited by: H.-P. Klenk 